\title{
RESENHA - Levitsky, Steven; Ziblatt, Daniel. How democracies die. Broadway Books, 2018.
}

\section{Natália Cordeiro Guimarães}

$\mathrm{O}$ argumento central dos autores é que se em períodos anteriores o declínio das democracias ocorria de forma nítida - quase inquestionável - por meio de golpes militares que faziam uso explícito da força e da coerção, nos dias atuais, o rompimento das democracias se dá de modo muito mais sutil. Os líderes eleitos democraticamente subvertem as instituições estabelecidas, contando com a aprovação das legislaturas e/ou cortes constitucionais para fazer valer suas próprias prioridades. Além disso, os meios de comunicação seguem com relativa liberdade de expressão, ainda que se imponham algumas autorrestrições para evitar problemas. Isso também se aplica à população em geral.

Os autores listam, entre outros, Venezuela, Hungria, Peru, Nicarágua, Rússia e Filipinas como exemplos de países em que as instituições foram paulatinamente alteradas e a fragilização da democracia foi travestida de legalidade. Para Levitsky e Ziblatt, devido à sutileza dos atuais mecanismos utilizados para colocar em risco as democracias, muitas pessoas não percebem de forma imediata as ameaças que lhes são infringidas. A linha que demarca a transição de um regime democrático para um autoritário tem adquirido contornos cada vez mais tênues, mas há alguns elementos que podem iluminar essa compreensão. Um deles é voltar o olhar para as experiências de outros países e aprender com elas, pois, segundo os autores, a história pode não se repetir, mas com frequência ela rima. Tal olhar permitiu, inclusive, que ou autores criassem um

Doutoranda em Ciência Política pela Universidade Federal de Pernambuco (UFPE), Recife, PE, Brasil. 
litmus test, espécie de teste que possibilita identificar políticos com tendências autoritárias antes que cheguem ao poder.

Os autores dizem ainda que, de tempos em tempos, emergem líderes demagogos mesmo nas democracias mais saudáveis. E, para que se considere robusta uma democracia, a capacidade de os líderes políticos e os partidos impedirem que populistas cheguem ao poder é um elemento central. Outra discussão fundamental feita diz respeito ao papel das instituições nas ocasiões em que líderes autoritários são eleitos. Isto é, os autores discutem se as instituições irão constranger tais atores ou se serão constrangidas pelos mesmos e, nesse sentido, argumentam que somente as instituições (pensadas do ponto de vista formal) não dão conta de salvaguardar a democracia.

Daí a relevância dos valores e normas democráticos não escritos; seriam eles que garantiriam que cortes, tribunais, legislaturas, mídia e mesmo o setor privado não sejam lenta, súbita e legalmente convertidos em "armas políticas" pelos populistas e ponham em risco as democracias. Nesse sentido, os autores pontuam dois elementos como fundamentais: a tolerância mútua - em que os atores políticos reconhecem a legitimidade de seus oponentes, esperando também terem a sua reconhecida - e o forbearance, o uso parcimonioso das prerrogativas institucionais conferidas aos líderes políticos.

Levitsky e Ziblatt têm uma visão pouco otimista de que, para além do enfraquecimento de tais normas não escritas, os desafios a serem enfrentados pela democracia norte-americana são ainda mais profundos, na medida em que a polarização política aprofundou os conflitos raciais e culturais existentes no país. Tendo sido feita esta contextualização do livro, serão discutidos de forma mais detida os principais argumentos de cada capítulo.

No primeiro capítulo se destrincha o conceito de "fateful alliance", segundo o qual, comumente, em contextos de crise, líderes populistas emergem como alternativas políticas e conseguem se eleger ao contar com o apoio de alguma elite política. Comumente tais elites veem o apoio a esses outsiders como uma janela de oportunidade para ascender ao poder, é como se "pegassem carona" na sua 
popularidade. $\mathrm{O}$ que a história, no entanto, tem mostrado - e para isso os autores dão os exemplos da ascensão de Hitler, Mussolini, Vargas e outros - é que, ao chegarem ao poder, os líderes populistas assumem as rédeas do mundo político, alterando paulatinamente as instituições e retirando protagonismo dessas elites que as apoiaram e sem as quais não teriam se eleito.

Esse processo pode ser evitado pelos partidos políticos ao barrarem, em suas instâncias decisórias, a candidatura de líderes autoritários. Nesse sentido, os partidos têm como uma de suas funções primordiais atuar enquanto gatekeepers da democracia. Os autores dirão ainda que, para que sejam impedidos de chegar ao poder, líderes populistas precisam ser identificados e, para isso, apresentam o litmus test, que desenvolvem com base nas discussões de Juan Linz. Os indicadores que devem nos deixar em alerta são: rejeição às normas e instituições democráticas; negação da legitimidade dos oponentes; tolerância ou incentivo à violência; e disposição para restringir liberdades dos oponentes. Basta que um político se enquadre em um desses para despertar preocupação.

No capítulo 2, é feito um resgate histórico do processo de gatekeeping nos Estados Unidos ao longo dos anos. A questão central para os autores é: por que em outros períodos não foi eleito um líder populista que se apresentasse como uma alternativa? Para Levitsky e Ziblatt isso se deveu não ao fato de terem inexistido candidatos com esse perfil, tampouco de não haver apoio popular a tais figuras. Isso se deveu à atuação dos partidos políticos que exerceram tanto o papel democrático de eleger os melhores representantes para os seus eleitores votarem, quanto o papel de filtragem de candidatos com perfil autoritário. Até hoje, essas funções eventualmente se tencionam entre si, mas o papel de filtragem, até o momento das eleições de Trump, vinha sendo (positivamente) saliente.

No terceiro capítulo, os autores retomam o processo em que a figura de Donald Trump coloca-se para disputar as eleições presidenciais nos EUA e argumentam que foi uma trajetória similar a de outros líderes outsiders que, àquela época, não foram muito longe na corrida eleitoral. Por que então o desfecho de Trump foi outro? 
De acordo com Levitsky e Ziblatt, isso se deveu a mudanças experimentadas em dois importantes mecanismos de gatekeeping: a flexibilização das formas de doação para as campanhas e a emergência das mídias alternativas, em especial a TV a cabo e as mídias sociais. Tais alterações dificultam que se barrem potenciais candidatos extremistas.

Além dos fatores apontados, os autores dizem que a eleição de Trump foi um caso em que os processos de gatekeeping nitidamente falharam e nos seus diferentes estágios - desde as "primárias invisíveis", passando pelas primárias, até as eleições em si. O que permeou o imaginário popular e do próprio partido republicano era de que o comportamento "polêmico" do magnata candidato não passava de "meras palavras". No entanto, Levitsky e Ziblatt alertam que, desde sempre, com base no litmus test, Trump deu sinais visíveis de ser um líder com tendências autoritárias e extremistas. Nesse sentido criticam duramente o partido republicano, por não ter sido capaz de barrá-lo de chegar tão longe.

No capítulo 4, são tratados os processos de subversão da democracia após a chegada dos líderes populistas ao poder. Os autores descrevem o caso de Fujimori no Peru, no qual uma sucessão de eventos imprevistos pôs em cheque o establishment político do país. Argumentam que, comumente, as instituições, que supostamente deveriam regular políticos autoritários, vão sendo gradativamente subvertidas. Todo esse processo é feito dentro da legalidade, dando aspecto de legitimidade às manobras realizadas. E não raramente isso ocorre sob os argumentos de combate à corrupção, melhoria da democracia ou por questões de segurança nacional. Nesse sentido, Levitsky e Ziblatt alertam para os riscos dessa transição sem alarde para o autoritarismo, que faz com que os cidadãos não percebam o risco que corre a democracia em seu país, ainda que isso ocorra diante de seus olhos.

O quinto capítulo se debruça sobre a seguinte questão: as instituições democráticas são facilmente subvertidas? Para tanto os autores retomam a história dos EUA, verificando que os mecanismos de checks and balances presentes na Constituição sempre foram 
eficazes no controle de possíveis abusos de poder. No entanto, argumentam que, por si só, tais instrumentos não são suficientes para salvaguardar a democracia, pois mesmo as instituições mais bem planejadas têm falhas e são passíveis de interpretação e, portanto, de disputa. Para Levitsky e Ziblatt, o elemento fundamental para manutenção da democracia é a robustez da difusão de normas informais democráticas na sociedade. Estas, por sua vez, também não atuam de forma isolada, mas em conjunto com as regras formais estabelecidas, se retroalimentando. Tais normas podem ser verificadas em diversas esferas da política norte-americana, mas as suas principais expressões são a tolerância mútua e o forbearance. Para justificar seus argumentos, os autores mobilizam diversos exemplos históricos e vão além, dizendo que ambas as normas, quando atuam juntas, têm potencial de reforçarem uma a outra, sendo o contrário também verdadeiro.

No sexto capítulo, é feito um resgate do surgimento das instituições informais que conformam a democracia dos EUA. De acordo com os autores, elas nem sempre existiram, tendo dado seus primeiros passos nos anos 1780 e 1790; até então havia uma profunda hostilidade, a qual os autores nomeiam de "hardball", entre Federalistas e Republicanos. O surgimento dos Democratas já se deu num momento em que valores democráticos estavam mais difundidos, no entanto esse processo não foi linear, tendo sido fortemente comprometido quando das discussões em torno da abolição da escravidão no país. A tolerância mútua só passou a ser uma realidade após a retirada da questão dos direitos civis e políticos dos negros da agenda, o que aprofundou as bases do apartheid norte-americano.

Com a consolidação da tolerância mútua, o forbearance foi encorajado. No século XX as regras democráticas estavam consolidadas e foram a base para o desenvolvimento do sistema de checks and balances onde Executivo, Legislativo e Judiciário operam articuladamente para manutenção da democracia. Sem tais normas, os freios e contrapesos dificilmente funcionam de forma eficaz. A despeito de ter havido momentos de risco à democracia norte-americana, 
eles foram contidos pelas instituições, fossem elas formais ou não. Ressalta-se ainda que a consolidação da democracia nos EUA esteve baseada num cruel sistema de exclusão racial.

Diante da discussão feita até então, o sétimo capítulo trata do início do processo de erosão da democracia norte-americana que, de acordo com os autores, começou bem antes do anúncio da candidatura (e conseguinte eleição) de Donald Trump. Nos anos 1980 e 1990, começou uma campanha dentro do Partido Republicano encampada por algumas lideranças - para desqualificação dos seus oponentes, os Democratas. Tal estratégia de hardball foi se intensificando, atingindo níveis extremos nos anos 2000. Para além disso, o Estado passou a quebrar algumas normas importantes, como o plano de redistritamento do Texas em 2003, e alguns setores midiáticos impuseram ainda mais tensão entre os partidos no contexto pós 11 de setembro.

As eleições de 2008 foram um momento crítico ante toda essa tensão, mais uma vez potencializado pela atuação de alguns setores da mídia hegemônica. Ao invés de iniciar uma era de conciliação, o governo Obama manteve acesas as tensões entre Democratas e Republicanos; a tolerância mútua foi nitidamente abandonada, sobretudo por parte dos Republicanos, que questionaram até mesmo a nacionalidade do presidente eleito. E a intolerância reduz a eficácia do forbearance; senadores democratas e Obama responderam com ações unilaterais. Além disso tudo, o que se via nos EUA, sustentam Levitsky e Ziblatt, era um aprofundamento da polarização política e, embora ainda não se soubesse, as consequências seriam graves.

No penúltimo capítulo, discute-se a chegada de Trump ao poder. Assim como outros líderes autoritários, o republicano atacou seus oponentes, referiu-se à mídia como "inimiga do povo americano" e questionou a legitimidade de juízes. Já nas primeiras semanas seu nome apareceu envolvido em escândalos e sua popularidade era baixíssima. E, mais grave que isso tudo, no seu primeiro ano de mandato, Trump já havia cooptado membros do Judiciário, marginalizado importantes atores políticos e reescrito regras para atender seus interesses. Os autores listam detidamente suas iniciativas em 
cada uma dessas esferas, demonstrando uma postura nitidamente autoritária.

Levitsky e Ziblatt, no entanto, dizem que ainda é cedo, pois o rompimento com a democracia requer tempo e alguns fatores podem influenciar esse processo, como a atuação dos líderes republicanos e líderes congressistas, o comportamento da opinião pública e a conjuntura. Argumentam ainda que eventuais quebras de normas pelos presidentes são quase inevitáveis e, eventualmente, benéficas, mas que o que Trump tem feito difere de tudo experimentado anteriormente e preocupa por ir no sentido oposto ao do fortalecimento democrático - a exemplo das situações em que mentiu e das graves ofensas que faz aos jornalistas. Mas talvez o alerta principal trazido pelos autores nesse capítulo diga respeito ao aumento da tolerância da sociedade norte-americana ante as quebras das normas e o risco que isso significa para a democracia, como se tais práticas já estivessem naturalizadas e fossem largamente aceitas.

O argumento final de "How democracies die?" é que a democracia dos EUA não é tão perfeita quanto se pensava; ela não está imune às ameaças autoritárias. Na realidade o processo de democratização estadunidense foi marcado por contradições, segregação racial e pelo jugo de um único partido. Somente após 1965, a democracia se efetiva no país, mas desde então o que se verifica é a intensificação da polarização política que tem levado a sucessivas quebras dos valores democráticos. Estaria então a democracia estadunidense em retrocesso como as de outras partes do mundo? Os autores são céticos quanto a essa crise global e falam no crescimento das democracias nos últimos anos, bem como no fortalecimento das existentes. Alertam, contudo, para a maneira como Trump vem conduzindo a política externa norte americana, retirando dela o papel de "promotora da democracia", nas palavras dos autores, e que isso pode sim levar a recessões democráticas a nível mundial.

De forma conclusiva, Levitsky e Ziblatt apontam três cenários possíveis pós Donald Trump: o mais otimista, o de retomada do fortalecimento da democracia no país. Nele, o magnata falharia em seu projeto político e não se reelegeria ou sofreria impeachment. 
Alertam que, embora caminho seja o desejo de muitos, ele é improvável, pois os passos que levaram a tal ordem vêm de antes. $\mathrm{O}$ segundo (e mais tenebroso) cenário seria aquele em que Trump e correligionários dariam seguimento aos seus intentos, ampliando seu poderio. E a terceira e mais provável possibilidade seria, após a saída de Trump, haver o aprofundamento da polarização política, mais desvios das normas democráticas informais e guerra institucional. Isto é, a fragilização dos principais elementos protetores da democracia norte-americana.

Nesse sentido, os autores sugerem que aqueles que desejam a retomada da democracia estadunidense busquem construir alianças pró-democráticas, ao invés de estimular a polarização, rearticulando as práticas de tolerância mútua e a forbearance. Para tanto, é fundamental estimular as distensões religiosa e racial e combater a crescente desigualdade social no país. Além de trazer uma leitura fluída e agradável, o livro reúne elementos interessantes para pensar a democracia e suas crises para além dos EUA, a partir dos contextos e realidades de cada localidade.

\section{Referência Bibliográfica}

LEVITSKY, Steven; ZIBLATT, Daniel. (2018). How democracies die.

New York: Broadway Books. 